\title{
EFFECT OF AMIODARONE IN PREVENTION OF ATRIAL FIBRILLATION IMMEDIATELY AFTER RELEASE OF AORTIC CROSS-CLAMP
}

\author{
LINGARAJ SAHU ${ }^{1 *}$, ALOK SAMANTARAY ${ }^{2}$, SHASHI SANKAR BEHERA ${ }^{3}$
}

${ }^{1}$ 1Department of Anaesthesiology, KIMS, Bhubaneswar,Odisa , India. ${ }^{2}$ Department of Anaesthesiology, Sri Venkateswara Institute of Medical Sciences, Tirupati, Andhra Pradesh, India. ${ }^{3}$ Department of Obstetrics and Gynaecology, KIMS, Bhubaneswar, Odisa Email: drlingarajsahu.2008@gmail.com/lingarajsahu.2008@rediffmail.com

Received: 13 October 2017, Revised and Accepted: 30 November 2017

ABSTRACT

Objective: The objective of this study is to determine the efficacy of a bolus dose of amiodarone administered by the way of cardiopulmonary bypass pump before releasing of aortic cross-clamp (ACC) in the prevention of atrial fibrillation.

Methods: In this prospective study, 22 non-diabetic patients were randomly assigned in a double-blind fashion to either amiodarone or placebo group. In amiodarone group injection amiodarone $3 \mathrm{mg} / \mathrm{kg}$ in $10 \mathrm{ml}$ normal saline (amiodarone group, Group A, n=10) and in control group (control group, Group P, n=12), the same volume of normal saline was administered 3 min before the release of ACC. Initial rhythm after the release of ACC was noted.

Results: The major rhythm after the release of ACC was ventricular arrhythmia in control group ( $\mathrm{n}=5$, 40\%), whereas in amiodarone group, it is normal sinus rhythm $(n=7,63 \%)$. Only the need of cardioversion/defibrillation and the amount of energy needed was less in the amiodarone group but not reached statistical significance level. There was a trend toward a higher ventricular rate in control group compared to amiodarone group, but it never reached statistical significance level $(114 \pm 46$ vs. $97 \pm 29, \mathrm{p}=0.3)$. One patient in amiodarone group required temporary pacemaker for sustained atrioventricular block with heart rate of $<50$ beats/min and continued on temporary pacemaker for $48 \mathrm{~h}$.

Keywords: Amiodarone, Atrial fibrillation, Aortic cross-clamp.

(C) 2018 The Authors. Published by Innovare Academic Sciences Pvt Ltd. This is an open access article under the CC BY license (http://creativecommons. org/licenses/by/4. 0/) DOI: http://dx.doi.org/10.22159/ajpcr.2018.v11i3.23097

\section{INTRODUCTION}

Atrial fibrillation (AF) is one of the most commonly encountered and sustained cardiac arrhythmias in clinical practice [1]. AF is associated with the risk of thromboembolic complications in $17-18 \%$ of patients $[2,3]$.

The pharmacological intervention in $\mathrm{AF}$ trial suggested that the maintenance of normal sinus rhythm (NSR) in patients with AF leads to symptomatic improvement [4]. However, the AF follow-up investigation of rhythm management study did not show any mortality benefit by the maintenance of sinus rhythm [1].

Postoperative AF occurs in $20-40 \%$ of patients undergoing open-heart surgery. The presence of AF after mitral valve replacement (MVR) is associated with a poor New York Heart Association (NYHA) Functional Classification, increased transmitral gradients, and larger areas of both atria [5].

Among all the antiarrhythmic drugs evaluated for AF, amiodarone has shown the most promising results with successful conversion and maintenance of NSR achieved in $50-70 \%$ of patients [6-8]. Oral amiodarone therapy needs frequent visits to the hospital and intense monitoring for side effects [9]. However, the onset of the antiarrhythmic effect of intravenous amiodarone is rapid $[10,11]$.

We evaluated the effect of intraoperative single dose of amiodarone by cardiopulmonary bypass pump before releasing of ACC to convert AF into NSR in patients undergoing valvular heart surgery.

\section{PATIENTS AND METHODS}

In this prospective study, 22 non-diabetic patients were randomly assigned in a double-blind fashion to either amiodarone or placebo group after obtaining approval from institute's Ethical Committee of SVIMS University. In amiodarone group injection amiodarone $3 \mathrm{mg} /$ $\mathrm{kg}$ in $10 \mathrm{ml}$ normal saline and in control group, the same volume of normal saline was administered 3 min before the release of ACC. The anesthesia, cardiopulmonary bypass ( $\mathrm{CPB}$ ), and surgical technique were standardized.

All patients scheduled for elective MVR surgery requiring CPB were included in the study. Written informed consent was obtained from all the patients. Patients were excluded if they were allergic to amiodarone, used amiodarone within the past 4 months of study, history of amiodarone toxicity, participating in another investigation protocol, thyroid disease, serum aspartate and alanine aminotransferase concentration more than 4 times the upper limit of normal, pregnant, resting heart rate (HR) of $<50$ beats/min, uncontrolled heart failure, sick sinus rhythm, atrioventricular (AV) heart block, and serum creatinine more than $2 \mathrm{mg} / \mathrm{dl}$.

Patients were prepared according to standard protocol. On the day before surgery, a standard coagulation profile, electrolytes, and complete blood count were done. All chronic diseases and medications were recorded. Pre-medications of ranitidine $150 \mathrm{mg}$ and alprazolam $0.5 \mathrm{mg}$ were administered orally, the night before proposed surgery. The patients remained nil orally for minimum period of $8 \mathrm{~h}$ before surgery.

On the day of surgery, patients were induced using a standardized anesthetic protocol consisting of fentanyl, midazolam, thiopentone, sevoflurane, and vecuronium. Anesthesia was maintained with sevoflurane, $50 \%$ oxygen in air. Patients were ventilated with volumecontrolled ventilation and a tidal volume of $10 \mathrm{ml} / \mathrm{kg}$ body weight. Respiratory rate was adjusted to maintain a $\mathrm{PaCO}_{2}$ of $35-40 \mathrm{mmHg}$. Electrocardiography (ECG), $\mathrm{SpO}_{2}, \mathrm{EtCO}_{2}$, arterial blood gas (ABG), 
invasive blood pressure, central venous pressure, nasopharyngeal temperature, and urine output were monitored.

Anticoagulation was achieved with injection of heparin $300 \mathrm{IU} / \mathrm{kg}$ body weight with additional heparin to maintain the satisfactory activated coagulation time. All surgeries were done with mild hypothermia and surface cooling of the heart with ice slush. CPB circuit was primed with ringer lactate and/or packed red blood cells to achieve hemoglobin of more than $9 \mathrm{~g} \%$. Myocardial protection was achieved with cold $\left(4^{\circ} \mathrm{C}\right)$ blood cardioplegic arrest (4:1 blood and crystalloid). ABG analysis was done at every $30 \mathrm{~min}$ during bypass period and $15 \mathrm{~min}$ before anticipated ACC release, and potassium and calcium were corrected to reference value as per institute's protocol. After replacement of valve, the patients were warmed actively to $37^{\circ} \mathrm{C}$ nasopharyngeal temperature.

The drug or saline was prepared and was administered in a random (computerized random number technique) manner 3 min before anticipated release of ACC, by a resident doctor who was not a part of this study.

\section{Data source}

Initial rhythm after the release of ACC was noted. If the patient was in $A F$, internal cardioversion was attempted with internal paddles for a maximum of three times with stepwise increasing energy (10J, 20J, 30J). If the patient was in NSR at aortic cross-clamp (ACC) release or after cardioversion with the HR of more than 60 beats/min, no intervention was done, if HR of $<60$ beats/min, atrial pacing (epicardial) was initiated. If the patient develops ventricular fibrillation or ventricular tachycardia, it was treated with internal defibrillation with stepwise increasing energy. If the patient was in AV block, AV sequential pacemaker (epicardial) was initiated. Time from the release of ACC to complete separation from extracorporeal circulation was monitored. Inotropic support was started if systolic blood pressure was $<90 \mathrm{mmHg}$. Decannulation was done after

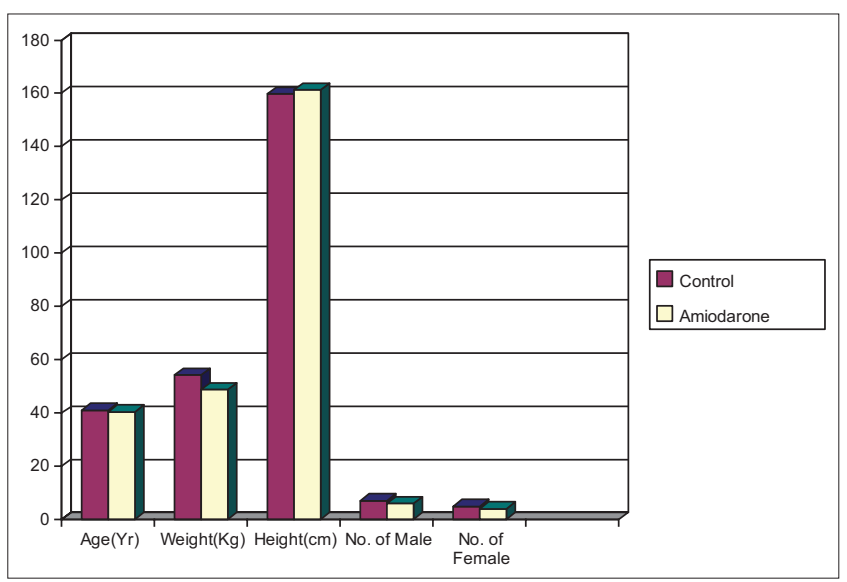

Graph 1: Demographic profile

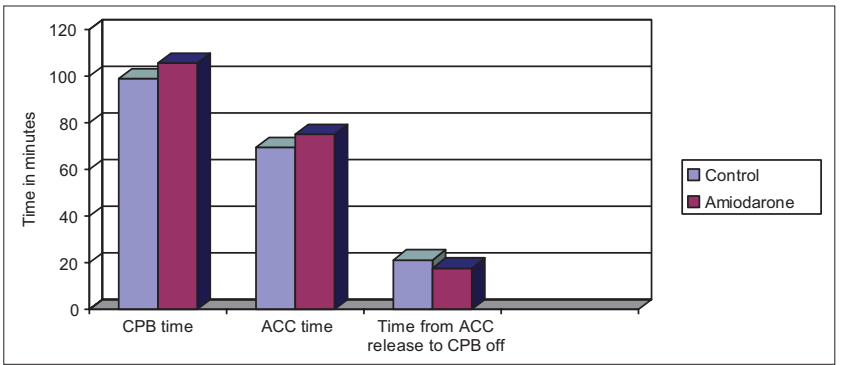

Graph 2: Intraoperative data. CPB: Cardiopulmonary bypass, ACC: Aortic cross clamp reversing anticoagulation with injection of protamine sulfate. After surgical closure, patients were shifted to post-operative intensive care unit (ICU) and were monitored for rhythm with five lead ECG. The recurrence of AF at the end of surgical procedure and in postoperative ICU was noted. At the end of study, the incidence of AF was compared in the placebo group versus the amiodarone group. Intraoperative data included CPB time, ACC time, total volume of cardioplegia used, ABG value, and electrolytes.

\section{Statistical analysis}

Comparison between two groups with respect to continuous variables, such as operative time (CPB and ACC), volume of cardioplegia used, and potassium level before ACC release was performed with student's $t$-test. Categorically, values such as sex ratio were analyzed using Chi-square test. All statistical analyses were done using SPSS (Statistical Packages for the Social Science, Chicago) 11.5 software. $p<0.05$ was considered statistically significant. The mean of the continuous variables is presented as mean \pm standard deviation.

\section{RESULTS AND OBSERVATIONS}

There was no significant difference in the patient characteristics anddemographic data (Graph 1, Table 1) between two groups. All the patients underwent MVR surgery for chronic rheumatic mitral valve disease except 2 from amiodarone and 1 from control group. The basal rhythm in all cases was AF with HR ranging from 70 to 122 beats/min, but there is no significant difference in basal HR between two groups (control group: $85 \pm 15.2$; amiodarone group: $98 \pm 22$, $\mathrm{p}=0.1$ ). All patients belong to either NYHA Class 2 or 3 classifications and were on oral digoxin $(0.25 \mathrm{mg})$ preoperatively. Atenolol $25 \mathrm{mg}$ orally once daily was given to 4 patients in control group and 2 patients in amiodarone group along with oral digoxin for effective rate control. Two patients from control group and three patients for amiodarone group have left arterial size more than $60 \mathrm{~mm}$.

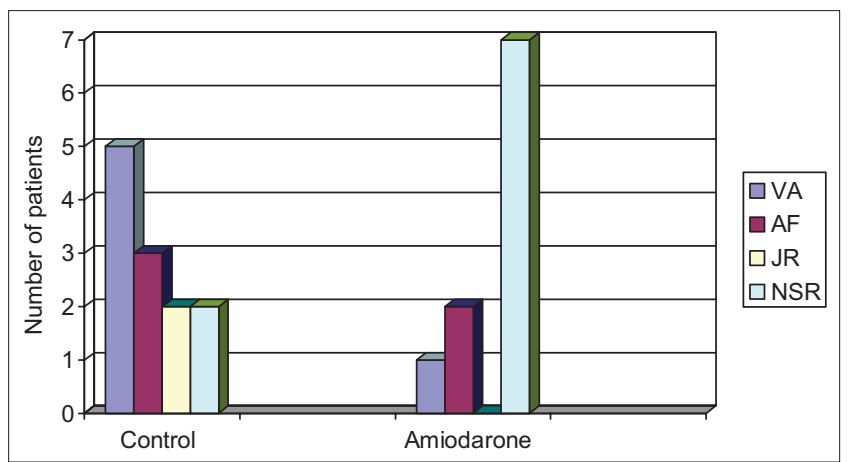

Graph 3: Initial rhythm after aortic cross-clamp release. VA: Ventricular arrhythmia, AF: Atrial fibrillation, JR: Junctional rhythm, NSR: Normal sinus rhythm

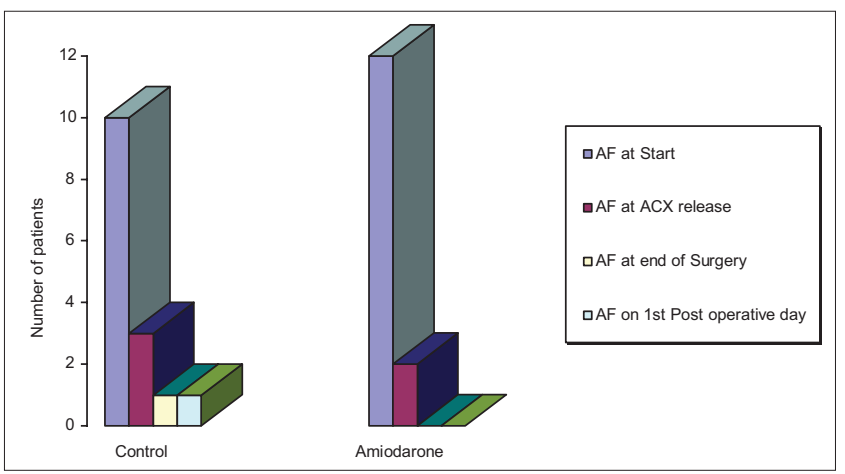

Graph 4: Number of patients with atrial fibrillation at varying time interval 
Table 1: Demographic data

\begin{tabular}{|c|c|c|c|}
\hline Patient variables & $\begin{array}{l}\text { Control } \\
\text { group }(n=12)\end{array}$ & $\begin{array}{l}\text { Amiodarone } \\
\text { group }(n=10)\end{array}$ & p \\
\hline Age (years) & $41.0 \pm 11.9$ & $40.4 \pm 9.9$ & 0.8 \\
\hline Male: female (n) & $7: 5$ & $6: 4$ & 1 \\
\hline Body weight (kg) & $54.2 \pm 10.2$ & $48.8 \pm 7.3$ & 0.1 \\
\hline Height $(\mathrm{cm})$ & $159.7 \pm 8.4$ & $161.3 \pm 8.2$ & 0.6 \\
\hline \multicolumn{4}{|l|}{ NYHA class } \\
\hline Class II & 7 & 6 & 1 \\
\hline Class III & 5 & 4 & \\
\hline \multicolumn{4}{|l|}{ Left ventricular function } \\
\hline 0-Normal & 11 & 7 & \\
\hline 1-Mild & 0 & 0 & \\
\hline 2-Moderate & 1 & 3 & \\
\hline 3-Severe dysfunction & 0 & 0 & 0.2 \\
\hline Digoxin & 12 & 10 & \\
\hline B-blocker & 4 & 2 & 0.6 \\
\hline Calcium channel blocker & 2 & 1 & 1 \\
\hline Type of heart surgery (n) & & & 0.5 \\
\hline MVR & 11 & 8 & \\
\hline DVR & 1 & 2 & \\
\hline $\begin{array}{l}\text { LA size in } \mathrm{mm} \\
\text { LA size }\end{array}$ & $55 \pm 10.4$ & $53.2 \pm 9.6$ & 0.6 \\
\hline$<45 \mathrm{~mm}$ & 1 & 1 & 0.3 \\
\hline $45-59 \mathrm{~mm}$ & 9 & 6 & \\
\hline$\geq 60 \mathrm{~mm}$ & 2 & 3 & \\
\hline History of CCF (n) & 3 & 1 & 0.5 \\
\hline
\end{tabular}

LA: Left atrium, NYHA: New York Heart Association Functional Classification, MVR: Mitral valve replacement, DVR: Double valve replacement. $p<0.05$ is statistically significant. $n$ : Number of patients. Data are presented as "mean \pm standard deviation" if not stated otherwise

Table 2: Intraoperative events

\begin{tabular}{llll}
\hline Intraoperative events & $\begin{array}{l}\text { Control } \\
\text { group (n=12) }\end{array}$ & $\begin{array}{l}\text { Amiodarone } \\
\text { group (n=10) }\end{array}$ & p \\
\hline CPB time (minutes) & $98.8 \pm 35.5$ & $105.5 \pm 34.7$ & 0.6 \\
ACC time (minutes) & $69.5 \pm 30.8$ & $75.1 \pm 29.0$ & 0.6 \\
Time to CPB off after the & $21.3 \pm 7.1$ & $17.8 \pm 6.5$ & 0.2 \\
release of ACC (minutes) & & & \\
Number of cold cardioplegia & $2.7 \pm 1.0$ & $2.9 \pm 0.9$ & 0.7 \\
Serum K'at the release of & $4.5 \pm 0.6$ & $4.3 \pm 0.3$ & 0.5 \\
ACC (mEq/l) & & & \\
Basal HR-beats/min & $85 \pm 15.2$ & $98 \pm 22$ & 0.1 \\
Use of antiarrhythmics for & 2 & 0 & 0.4 \\
VT/VF & & & \\
Inotrope use (n) & & 6 & \\
$\quad$ Dopamine & 4 & 2 & \\
$\quad$ Dopamine+adrenaline & 7 & 1 & 0.2 \\
$\quad$ Dopamine+isoprenaline & 1 & 1 & \\
$\quad$ Milrinone & 0 & $1.8 \pm 0.6$ & 0.1 \\
T.BT (units) & $1.8 \pm 0.3$ & $9.7 \pm 5.4$ & 0.4 \\
T.FFP (units) & $2.1 \pm 0.3$ & $6.1 \pm 0.3$ & $0.02^{* *}$ \\
Extubation time (hours) & $11.03 \pm 5.2$ & $6.7 \pm 0.7$ & \\
ICU stay (days) & & & \\
\hline
\end{tabular}

T.BT: Units of blood transfused, T. FFP: Units of fresh frozen plasma transfused, CPB: Cardiopulmonary bypass, ACC: Aortic cross-clamp; HR: Heart rate,

VT: Ventricular tachycardia, VF: Ventricular fibrillation. Data are presented as

"mean \pm standard deviation" if not stated otherwise. ICU: Intensive care unit

The CPB time, ACC time (Graph 2, Table 2) and number of cold cardioplegia were comparable between two groups. The mean serum $\mathrm{K}+$ level before the release of ACC was within the reference range (control group: $4.5 \pm 0.6$; amiodarone group: $4.3 \pm 0.3 \mathrm{mEq} / \mathrm{L}, \mathrm{p}=0.5$ ). Dopamine was the main inotrope in all cases in the post-bypass period to maintain the hemodynamics. Isoprenaline was used in two cases (one for each group) for maintaining HR above 50 beats/min. One patient from amiodarone group was weaned with support of milrinone for severe pulmonary hypertension. Two patients from amiodarone group required additional dose of $5 \mathrm{ml}$ xylocard $2 \%$ along with DC
Table 3: Primary outcome

\begin{tabular}{|c|c|c|c|}
\hline Primary outcome & $\begin{array}{l}\text { Control } \\
\text { group } \\
\mathrm{n}=12(\%)\end{array}$ & $\begin{array}{l}\text { Amiodarone } \\
\text { group } \\
\mathbf{n = 1 0}(\%)\end{array}$ & $\mathbf{p}$ \\
\hline $\begin{array}{l}\text { First rhythm after the ACC } \\
\text { release }\end{array}$ & & & $0.05^{* * *}$ \\
\hline Ventricular arrhythmias & $5(40)$ & $1(9)$ & \\
\hline $\mathrm{AF}$ & $3(24)$ & $2(18)$ & \\
\hline JR & $2(16)$ & $0(0)$ & \\
\hline NSR & $2(16)$ & 7 (63) & \\
\hline Others & 0 & 0 & \\
\hline $\begin{array}{l}\text { Number of patients } \\
\text { responding to } \\
\text { cardioversion/defibrillation }\end{array}$ & 7 & 2 & 0.09 \\
\hline $\begin{array}{l}\text { Number of cardioversion/ } \\
\text { defibrillation needed }\end{array}$ & $0.6 \pm 0.6$ & $0.5 \pm 1.03$ & 0.6 \\
\hline $\begin{array}{l}\text { Amount of energy } \\
\text { needed (joules) }\end{array}$ & $7.5 \pm 11.1$ & $5.0 \pm 10.0$ & 0.6 \\
\hline AF at end of surgery (n) & $1(8)$ & $0(0)$ & 0.5 \\
\hline Recurrence of AF in ICU (n) & $1(8)$ & $0(0)$ & 0.5 \\
\hline Need of TPI (n) & $0(0)$ & $1(9)$ & 0.4 \\
\hline $\begin{array}{l}\text { AF at } 1^{\text {st }} \text { post-operative } \\
\text { day (n) }\end{array}$ & $1(8)$ & $0(0)$ & 0.5 \\
\hline $\begin{array}{l}\text { Ventricular rate in patients } \\
\text { with AF-beats } / \mathrm{min}\end{array}$ & $114 \pm 46$ & $97 \pm 29$ & 0.3 \\
\hline
\end{tabular}

shock in the post-ACC release period to maintain pulsating rhythm. All the patients were extubated within $4-16 \mathrm{~h}$ and the time to extubation was comparable in both groups (control group: $11.03 \pm 5.2$; amiodarone group: $9.7 \pm 5.4, p=0.4)$. The ICU stay was significantly more in control group compared to amiodarone group $(\mathrm{p}=0.02)^{* *}$.

The major rhythm after the release of ACC was ventricular arrhythmia in control group $(n=5,40 \%)$, whereas in amiodarone group, it is NSR $\left(n=7,63 \%, p=0.05^{* * *}\right)$. Only the need of cardioversion/defibrillation and the amount of energy needed was less in the amiodarone group but not reached statistical significance level. There was a trend toward a higher ventricular rate in control group compared to amiodarone group, but it never reached statistical significance level $(114 \pm 46$ vs. $97 \pm 29, p=0.3$ ). One patient in amiodarone group required temporary pacemaker for sustained $\mathrm{AV}$ block with $\mathrm{HR}$ of $<50$ beats/min and continued on temporary pacemaker for $48 \mathrm{~h}$ (Table 3).

\section{DISCUSSION}

Amiodarone (2-butyl-1-benzofuran-3-yl)-[4-[2-(diethylamino) ethoxy]-3,5- diiodophenyl]methanone, a Class III antiarrhythmic agent in the Vaughan Williams scheme [12], is the most efficacious agent for reducing ventricular arrhythmias and suppresses the incidence of post-myocardial infarction sudden death [13]. Intravenous amiodarone has become one of the most frequently administered intravenous antiarrhythmics in cardiac surgery because of its broad spectrum of efficacy. Amiodarone is an unusual Class III antiarrhythmic that produces each of the four main types of antiarrhythmic action according to Vaughan Williams classification [12]. It displays a wide cellular electrophysiological spectrum inhibiting the potassium currents as well as sodium currents and L-type calcium currents in isolated cardiomyocytes [14].

Some case series have reported an increased risk of marked bradycardia and hypotension immediately after cardiac surgery in patients already on amiodarone at the time of surgery [15]. Other case-control studies, however, have not reproduced this finding. None of the placebocontrolled trials of prophylactic amiodarone for perioperative AF prevention found any adverse cardiovascular effective of the drug [16]. Thus, it is unlikely that amiodarone poses a serious cardiovascular 
risk to the post-operative patients. In our study, we used a low-dose amiodarone of $150 \mathrm{mg}$ through pump and did not find any significant difference in time from the time to release the ACC to weaning from $\mathrm{CPB}$ in both the groups (control group, 21.3 $\pm 7.1 \mathrm{~min}$; amiodarone group, $17.8 \pm 6.5 \mathrm{~min} ; \mathrm{p}=0.2$ ). One patient in amiodarone group required temporary pacemaker for sustained AV block with HR of $<50$ beats $/ \mathrm{min}$ and continued on temporary pacemaker till discharge from ICU.

Spontaneous sinus rhythm was observed in seven patients in amiodarone group compared two patients in control group. Two patients from amiodarone group had recurrence of AF out of which one patient responded to cardioversion/defibrillation and reverted back to NSR at the end of surgery. One patient who did not respond to cardioversion/defibrillation continued to have AF till discharge.

Left atrial size is a known risk factor for the occurrence of AF in postACC release $[17,18]$. Out of five patients with left atrial size $\geq 60 \mathrm{~mm}$, three patients (60\%) had AF (two from amiodarone group and one from control group), and out of 15 patients with left atrial size between 45 and $59 \mathrm{~mm}$, two patients from control group continued to have AF in the post-ACC release period, but from amiodarone group, all the patients demonstrated either spontaneous NSR or NSR after DC shock therapy.

In our study, total five patients had recurrence of AF in their initial rhythm after the release of ACC (two from amiodarone group and three from control group). Those two patients from amiodarone group who had recurrence of AF after the release of ACC had left atrial size of $\geq 60 \mathrm{~mm}$, but in the control group, those three patients who had recurrence of AF after the release of ACC, one patient had left atrial size $>60 \mathrm{~mm}$ and rest two had left atrial size between 45 and $59 \mathrm{~mm}$

Although the ICU stay was prolonged in control group $(6.7 \pm 0.7$ days $)$ compared to amiodarone group $(6.1 \pm 0.3), p=0.02$, we could not comment on this as we have not set any discharge criteria from ICU in our original study protocol.

There was a significant difference in the total blood transfusion intraoperatively; the amount of blood transfusion required in the control group was $(1.8 \pm 0.3$ units) higher than the amiodarone group $(1.4 \pm 0.5$ units); however, we did not randomize all the factors affecting the blood transfusion; therefore, we are considering that it is an incidental finding in our study.

\section{CONCLUSION}

We suggest the regular use of amiodarone (150 mg) in practice, and we also recommend further study to find the effect of amiodarone in the prevention of AF immediately after the release of ACC and also during ICU stay.

\section{AUTHORS' CONTRIBUTION}

Dr Lingaraj Sahu and Dr Alok Samantaray involved in the conception, proposal writing, data collection, and drafted the paper. Dr Lingaraj Sahu, Dr. Alok Samantaray and Dr. Shasi Sankar Behera contributed in statistics and data analysis. All the authors read and approved the final manuscript.

\section{CONFLICTS OF INTERESTS}

The authors declare that they have no conflicts of interests. We did not have any financial support and personal relationship that might inappropriately influence us in writing this paper.

\section{REFERENCES}

1. Wyse DG, Waldo AL, DiMarco JP, Domanski MJ, Rosenberg Y, Schron EB, et al. A comparison of rate control and rhythm control in patients with atrial fibrillation. N Engl J Med 2002;347:1825-33.

2. Kannel WB, Abbott RD, Savage DD, McNamara PM. Epidemiologic features of chronic atrial fibrillation: The Framingham study. N Engl J Med 1982;306:1018-22.

3. Alpert JS, Petersen P, Godtfredsen J. Atrial fibrillation: Natural history, complications, and management. Annu Rev Med 1988;39:41-52.

4. Hohnloser SH, Kuck KH, Lilienthal J. Rhythm or rate control in atrial fibrillation - pharmacological intervention in atrial fibrillation (PIAF): A randomised trial. Lancet 2000;356:1789-94.

5. Vaturi M, Sagie A, Shapira Y, Feldman A, Fink N, Strasberg B, et al. Impact of atrial fibrillation on clinical status, atrial size and hemodynamics in patients after mitral valve replacement. J Heart Valve Dis 2001;10:763-6.

6. Roy D, Talajic M, Dorian P, Connolly S, Eisenberg MJ, Green M, et al. Amiodarone to prevent recurrence of atrial fibrillation. Canadian trial of atrial fibrillation investigators. N Engl J Med 2000;342:913-20.

7. Chun SH, Sager PT, Stevenson WG, Nademanee K, Middlekauff HR, Singh BN, et al. Long-term efficacy of amiodarone for the maintenance of normal sinus rhythm in patients with refractory atrial fibrillation or flutter. Am J Cardiol 1995;76:47-50.

8. Kochiadakis GE, Igoumenidis NE, Marketou ME, Solomou MC, Kanoupakis EM, Vardas PE, et al. Low-dose amiodarone versus sotalol for suppression of recurrent symptomatic atrial fibrillation. Am J Cardiol 1998;81:995-8

9. Chakraborty A, Mondal C, Sinha S, Mandal J, Chandra AK. Amiodarone induced oxidative stress in stress - Vulnerable organs of adult male rats. Asian J Pharm Clin Res 2014;7:177-83.

10. Installe E, Schoevaerdts JC, Gadisseux P, Charles S, Tremouroux $\mathrm{J}$. Intravenous amiodarone in the treatment of various arrhythmias following cardiac operations. J Thorac Cardiovasc Surg 1981;81:302-8.

11. Singh BN, Vaughan Williams EM. The effect of amiodarone, a new anti-anginal drug, on cardiac muscle. Br J Pharmacol 1970;39:657-67.

12. Vaughan William EM. A classification of antiarrhythmic agents reassessed after a decade of new drugs. J Clinpharmacol 1984; 24:129.

13. Connolly SJ. Evidence based analysisof amiodarone efficacy and safety. N Engl J Med 1990;322:863-8.

14. Kodama I, Kamiya K, Toyama J. Cellular electropharmacology of amiodarone. Cardiovasc Res 1997;35:13-29.

15. Rady MY, Ryan T, Starr NJ. Preopeative therapy with amiodarone and the incidance of acute organ dysfunction after cardiac surgery. Anesth Analg 1997;337:1785

16. Carlson MD. How to manage atrial fibrillation: An update on recent clinical trials. Cardiol Rev 2001;9:60-9.

17. Brodsky MA, Allen BJ, Walker CJ $3^{\text {rd }}$, Casey TP, Luckett CR, Henry WL, et al. Amiodarone for maintenance of sinus rhythm after conversion of atrial fibrillation in the setting of a dilated left atrium. Am J Cardiol 1987;60:572-5.

18. Selvaraj T, Kiran U, Das S, Chauhan S, Sahu B, Gharde P, et al. Effect of single intraoperative dose of amiodarone in patients with rheumatic valvular heart disease and atrial fibrillation undergoing valve replacement surgery. Ann Card Anaesth 2009;12:10-6. 